\title{
A Novel Policy Making Proposition for EV Charging Infrastructure Management at HEI's
}

\author{
Yaminidhar Reddy Bhavanam \\ Brunel Institute of Power Systems \\ Brunel University, Uxbridge, London. UK \\ yaminidhar.bhavanam@brunel.ac.uk \\ Peter Berresford, Director \\ Department of Operations \\ Brunel University, Uxbridge, London, UK \\ peter.berresford@brunel.ac.uk
}

\author{
Prof.Gareth Taylor, Director \\ Brunel Institute of Power Systems \\ Brunel University, Uxbridge, London, UK \\ gareth.taylor@brunel.ac.uk \\ Jill Langsman, CSM \\ Department of Operations \\ Brunel University, Uxbridge, London, UK \\ jill.langsman@brunel.ac.uk
}

\begin{abstract}
This paper is based on real time EV charging infrastructure development that took place at Brunel University, which is located in west of London, UK. The aim of this paper is to establish the policy making process that has stages of an initial student-staff interest survey, records of the consultation process with EV owners, results of competitive benchmarking with other HEI's and the discussion on Type 2 Mode 3 charging stations which are $240 \mathrm{~V}, 32 \mathrm{~A}, 7 \mathrm{~kW}, 50 \mathrm{~Hz}$ compliant with IEC 62196 and ISO 14443 Mifare standards. The first time ever PAYG concept of POD Point Ltd is explained. Benefits of using PAYG concept for charging EV are mentioned. Various other factors that played major role were also considered as follows: deciding the tariff of the electricity used by the EV owners, charging cable compatibility with charging station, hours of operation, creation of new enforcement rules and recommendations to provide incentives that recognise and motivate EV community.
\end{abstract}

Index Terms- Charging Infrastructure, Charging Mode, Competitive Benchmarking, Electric Vehicles, Enforcement, Higher Education Institutions, Incentive, Questionnaire, Standards, Tariff, Transport

\section{INTRODUCTION}

The evolution of electric vehicles (EV) is revolutionising the automobile industry. However, the impact of EV is not confined to the automobile industry, its association with the power sector, vast charging infrastructure development, zero greenhouse gas emissions and other related businesses or commercial developments are yet to be realised. The full potential of EV will only be realised when there is efficient infrastructure and appropriate administration by proper standards and policies. EV charging infrastructure development is given higher priority at homes and public places when compared with workplace charging. In recent times EV manufacturers and government focus on workplace charging is becoming the higher priority. The UK government has now declared grant funding for up to $75 \%$ of the capital expenditure incurred as a result of purchase and installation of work place charge points. EV charging infrastructure management at Higher Educational Institutions (HEI's) is completely different to that of workplace charging in general as there will be various categories of users i.e. students, staff and visitors. Brunel University is the case study used in this research. The electric vehicle supply equipment (EVSE) that are established at Brunel University are manufactured by Pod Point Ltd. These EVSE are termed as charging stations or Pod Point's or Pods where necessary throughout this paper.

In this paper Section II describes the strategy that has been followed in order to initiate the research and to escalate it further. The identification process of the availability of the Pod Point's in order to charge an EV, charging cable compatibility, electrical properties of the charging stations, first time ever PAYG concept to use Type 2 Mode 3 charging stations that are manufactured by Pod Point Ltd are explained in Section III. Section IV consists of key findings from benchmarking (seven HEI's). Section V states the recommendations made based on the learning outcomes of the research to the Chief Operating Officer, Brunel University. Conclusions were made in Section VI.

\section{POLICY DEVELOPMENT STRATEGY}

With the help of government funding from Office of low emission vehicles, Department of Transport and the associated company Pod Point Ltd that installs the electric vehicle charging stations, it is really important to develop a reasonable and acceptable policy for the present and future EV community at Brunel University.

\section{A. Student, Staff interest survey}

Annual travel survey is conducted every year by the department of operations in order to improve the travel and parking arrangements at Brunel University. Two questions were made part of that survey to identify the existing and future EV users. The questions are:

\section{Do you drive an electric vehicle to Brunel?}

2. Do you have any plans to purchase an electric vehicle in the next 12 months?

Seventeen people positively responded for the above questions. Seven are driving an EV to Brunel University and ten have plans to purchase an EV in the next 12 months.

\section{B. Discussion with present and prospective EV owners}


As part of the consultation process, open discussion and personal interviews were conducted with people identified. Topics discussed were regarding availability, usage, compatibility of charging cable, electricity tariff, hours of operation of Pod Point, enforcement and incentives. Additional questionnaire was developed to further understand the EV community. The questions are:

1. What made you to buy or consider to buy an EV

2. Please specify the make and model of the EV you wish to recharge.

3. Does the charging cable become barrier to use the charging facility

4. How much time you think you need to top up the charge of your vehicle

5. If you are an existing user of EV, what is the nearest public charging station to university that you are using in case you need to. Please mention the location along with postcode.

6. Do you think you should be eligible for any incentive because of driving a zero carbon emission vehicle into university

7. What incentive you prefer

Summary: Novelty, reducing carbon emissions, tax avoidance, cutting costs are responses to the first question. $80 \%$ of Brunel's EV community responded that they are owners of Nissan Leaf. Charging cable does seem to be a barrier in utilising the facility of charging stations at Brunel University because the domestic cable that is supplied during the purchase of the vehicle is not compatible with the charging stations that are available on campus. Compatibility of charging cable with charging stations is discussed in Section III in detail. $60 \%$ of the EV owners need at least 3 hours of charging for their EV's while they are at university. All the present and prospective EV owners responded that they should be eligible for incentives. $100 \%$ of EV community at Brunel University are worried about the parking space to park their EV after charging it.

\section{Competitive Benchmarking}

Seven UK HEI's which has established EV charging stations for its users are considered to compare and draw conclusions on various aspects [1]. Universities considered are:

1. Kingston University, London

2. University of Bath

3. Homerton University Hospital

4. National Oceanography Centre, University of Southampton

5. Nottingham Trent University

6. Northumbria University, Newcastle

7. Teesside University

Learning outcomes and key findings from benchmarking are discussed in Section IV.

\section{USING TYPE 2 MODE 3 CHARGING STATIONS}

EVSE are manufactured, supplied and installed by a company named "Pod Point". Pod Point is a wholly owned brand of Pod Point Ltd. This company is responsible for the overall user experience at Brunel University. Brunel takes major decisions such as, tariff for the PAYG users (staff, students and the visitors of the university) and the hours of operation of the Pod Points. This helps to ensure that the service being provided is usable and within the reach of everyone.

Brunel's commitment to show impact on the environmental priorities such as climate change, air quality, decarbonisation, green growth and green travel will remain focussed and every development and decision in its progress will be taken on their own merit. This new establishment of Pod Points in the long term will have positive mark in reducing the carbon emissions within the campus, improves the air quality and gives strength to the green travel.

\section{A. Pod Point Status}

The blue, green and red highly visible status lights present along the side of the Pod Point will allow the EV drivers to understand from distance whether the unit is available for use, already in use (vehicle is being charged) or out of service. In addition to this the live availability map on Pod Point website will help to know the status of the nearest Pod Point. Live availability map can be accessed with this web link: http://www.pod-point.com/live-availability [2]

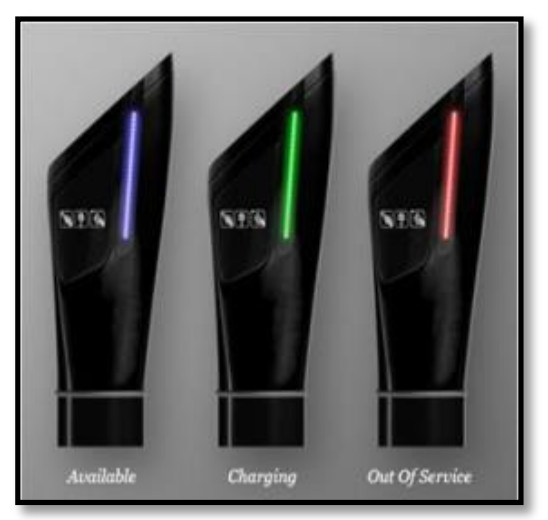

Fig. 1. Pod Point's highly visible status lights Source: www.pod-point.com

\section{B. Pod Point socket, compatible cable}

The Pod Point twin Mennekes 32-32 post delivers 32 A of output current or $7 \mathrm{~kW}$ of output power from each socket. Two electric vehicles can undergo fast charge simultaneously from a single post. The Pod Point pillar has mennekes sockets and therefore one end of the cable that needs to be connected to the Pod Point should be compatible to them. The standard domestic lead supplied with the electric car is not useful to plug in. 7 pin Type 2 Mode 3 (Mennekes) cable is required. [3] 


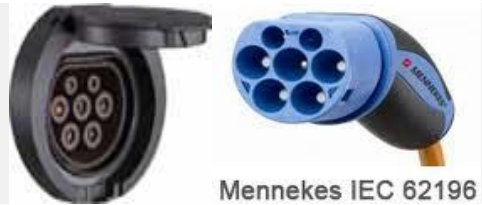

Fig. 2. Mennekes socket and one end of the charging cable Source: www.mennekes.ru

\section{Electrical Properties of the Pod Point}

Pod Point has several electrical properties and the important ones in a nutshell are as below:

TABLE I

ELECTRICAL PROPERTIES OF POD POINT

\begin{tabular}{|l|l|}
\hline Charge Type & Mode 3 \\
\hline Number of Charge Sockets & 2 per each pillar \\
\hline Rated Voltage & $240 \mathrm{~V}$ \\
\hline Rated Output Current & $2 * 32 \mathrm{~A}$ \\
\hline Rated Output Power & $7 \mathrm{~kW}$ \\
\hline Rated Frequency & $50 \mathrm{~Hz}$ \\
\hline Over current Protection & $32 \mathrm{~A}$ per door \\
\hline Ground fault protection & $32 \mathrm{~mA} \mathrm{RCD}$ \\
\hline Socket Electrical Compliance & IEC 62196-2 \\
\hline RFID Reader Compliance & ISO 14443 Mifare \\
\hline RFID Reader Frequency & $13.56 \mathrm{Mhz}$ \\
\hline Standby Power consumption & $5 \mathrm{~W}$ \\
\hline Source:http:/www.pod-point.com/wp-content/uploads/2011/08/PP-
\end{tabular}

DATASHEET-twin-charge-32-32.pdf

\section{Usage of Pod Point [4]}

\section{a) Sign up/ Registration}

Electric vehicle owners must get registered by calling the Pod Point's call centre to use the charging facility. The telephone number to be contacted on is 02072474114 . The free registration process securely collects and stores the following data:

- Name and Address

- Mobile Telephone Number

- E-mail address

- A method of payment :credit or debit card details

A small initial balance (say £10) is taken and the users account balance is updated in the user login account page where they can view their usage profile.

b) Pricing/ Tariff at a charging station

Pricing at a charging station is not same at all places. Every charging station has an identification number (example: 9422134). User may wish to check the price before charging the EV; this can be done by texting (standard network texting charges may apply) a given number in the similar manner below:
Example:

SMS to 6\#\#\#\#: "TARIFF 9422134”

Response to user: "Site A 9422134: £0.71 per hour. Text START 9422134 to begin charging".

c) To start charging

In order to start charging the electric vehicle after parking in a dedicated bay, user will need a compatible charging cable and a mobile phone.

Step 1: Plug one end of the cable to the vehicle

Step 2: Trigger the socket to open and the charge cycle to start by sending a text message to the system message centre.

SMS to 6\#\#\#\#: "START 9422134"

Step 3: The available socket door will be released

Step 4: Plug the other end of the cable into the socket which will be locked

Response to user: "Site A 9422134 Charging. To end Text STOP 9422134”.

Step 5: Highly visible status lights change colour from blue to green on the corresponding socket to indicate that charging has started.

\section{d) To stop charging}

Step 1: The user stops the charge cycle and release their cable by sending a text message to the system message centre.

\section{SMS to 6\#\#\#\#: "STOP 9422134"}

Step 2: The highly visible status lights change colour from green to blue on the corresponding socket to indicate that charging has stopped and it is available for the next user.

Step 3: The lock will be released and the cable can be removed from the socket.

Response to user: "Site A 9422134 stopped. 24 kWh delivered over 4 hours. Total cost $£ 2.83$. Login for more details. Thank you."

Step 4: Close the socket door firmly

Step 5: Unplug cable from car

$$
\text { e) PAYG (Pay As You Go) }
$$

During the process of registration, user debit or credit card details are taken as a method of payment. Minimum amount (say £10) is charged and the user's account balance is updated to $£ 10$. A dedicated user account page is set up after the registration process for every individual end user. Account can be 
credited by dialling 02072474114 when required. After each usage (sending START and STOP text message) an entry is made on the user account page recording the number of kilowatt hours delivered, usage time (charging cycle) and the users balance is updated.

\section{KEY FINDINGS FROM BENCHMARKING}

\section{A. Learning Outcome 1: Public and PAYG charging networks}

There are public and PAYG charging networks in UK, where a public charging network is one where EV drivers join a public network (usually by paying annual membership fee), and that gives them access to all charge points on that particular network using an RFID tag. There are two types of public charging networks:

1. "Government Plugged in Places networks:

Plugged in Places (PiP) is a government initiative in regions across the UK. Fig. 3 shows the five currently active regions in green, and three further regions expected to be active in grey.

\section{The Pod Point Open Network}

For areas not covered by a Plugged in Places network, the Pod Point Open Network provides a public charging network for EV drivers and for businesses who want their charge points to be included in a public charging network." [5]

“The Pod Point PAYG Network is Europe's first pay as you go electric vehicle charging network. It allows anyone with a mobile phone to access charging points across the UK. There is no membership fee - anyone can use the charge points.

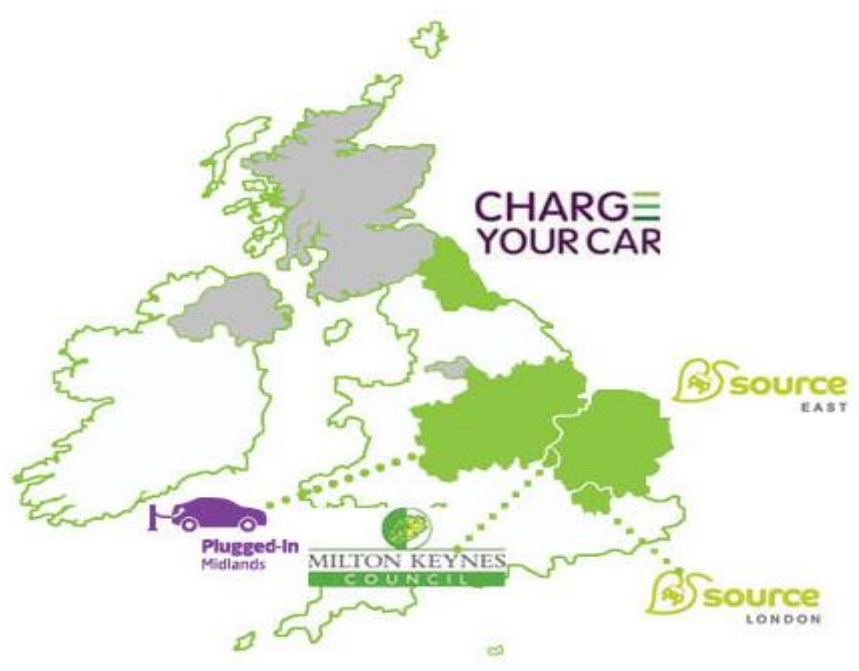

Fig.3: EV public charging networks in UK Source: www.pod-point.com
The benefits of using PAYG network are:

1. EV drivers pay no yearly membership fees, instead they pay only for what they use

2. No RFID tags are needed - just a mobile phone, so drivers don't need to pre-register and wait for a tag to arrive in the post before using a charge point

3. A user login account where they can view their usage profile

4. Call centre support line in case of any charging problems." [6]

\section{B. Learning Outcome 2: Status of EV infrastructure at HEI's}

Table 2 shows how the $25 \%$ funding was made available by the universities, what type of network the universities are with, whether the usage of RFID card is required for access to charging stations and how much membership fees is being paid by the EV users for the usage of those charging networks at respective universities. Most of the universities funded the $25 \%$ of investment from their own budgets. Other than Brunel all HEI's are part of public charging networks. Southampton University has unique feature where a pre booking of space, time are required and payment has to be made in advance (before 48 hours). Though RFID card is required to access the EV charging station like all other public charging networks, the prepaid process made it likely to fall under PAYG network. HEI's except Brunel requires RFID cards/tags in order to get access to EVSE and pays the membership fee as mentioned in Table 2. Electricity is provided free of cost for the EV users who are part of public charging networks. PAYG users will pay for what they use and the tariff is set up by the facility providers (university management).

\section{Learning Outcome 3: Annual parking permit fee}

Other parameter that was considered for the study is the amount of parking permit fee paid by the students and staff annually at the universities where there is parking facility. Staff at universities pays the parking fee according to their salary $(0.3 \%$ of the salary of the staff member at Brunel University). Parking permit fee paid by staff who earns $£ 25 \mathrm{k}$ per annum at HEI's are considered in this research. Fig.4 shows the graphical representation of student staff annual parking permit fee paid. Although parking fee is charged there is no guarantee of parking space and the process of hunting is required. This drawback gave scope for incentivising (concession in parking permit fee) EV users which in turn makes others motivated to use EV 
TABLE II

COMPARISON OF VARIOUS PARAMETERS AT HEI'S

\begin{tabular}{|l|c|c|c|c|c|}
\hline \multicolumn{1}{|c|}{ University } & Funding & Public/ & Network & RFID tags/cards & Annual Membership fee \\
& & PAYG & & Required & $£ 12.50$ \\
\hline University of Bath & Self & Public & Pod Point & Required & $£$ Rot Applicable \\
\hline University of Southampton & Self & PAYG & Plugged in Places & Required & $£ 10.00$ \\
\hline Northumbria University Newcastle & Self & Public & Charge Your car & Required & $£ 10.00$ \\
\hline Teesside University & Self & Public & Charge your car & Required & $£ 10.00$ \\
\hline Homerton University Hospital & Self & Public & Source London & Required & $£ 20.00$ \\
\hline Kingston University & Council & Public & Source London & Required & Not Required \\
\hline Nottingham Trent University & Self & Public & Plugged in Midlands & Not Applicable \\
\hline Brunel University & Self & PAYG & Pod & & \\
\hline
\end{tabular}

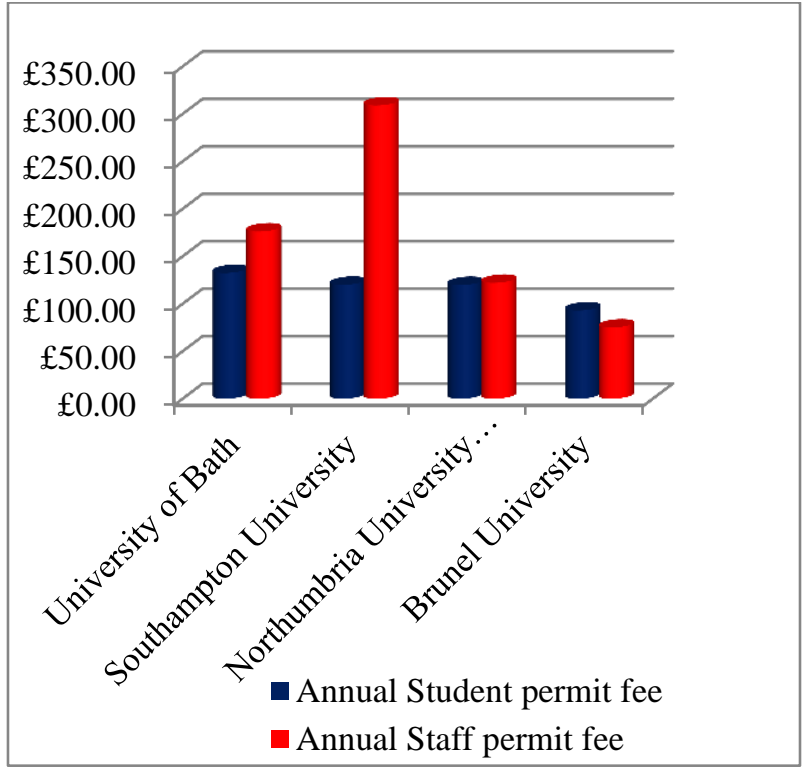

Fig. 4. Annual student \& staff parking permit fee at HEI's

\section{Learning Outcome 4: No. of charging bays and stations}

Fig.5 depicts the number of charging stations and dedicated charging bays at HEI's. Only two ports EVSE are installed under this government grant. It can be observed that the charging bays are twice to that of the charging stations. Once the EV's are charged they have to be moved to normal parking bays giving opportunity for other EV users to charge. This finding also gave scope to include in recommendations the provision of reserved parking spaces and access to both student and staff parking areas as an incentive to EV users.

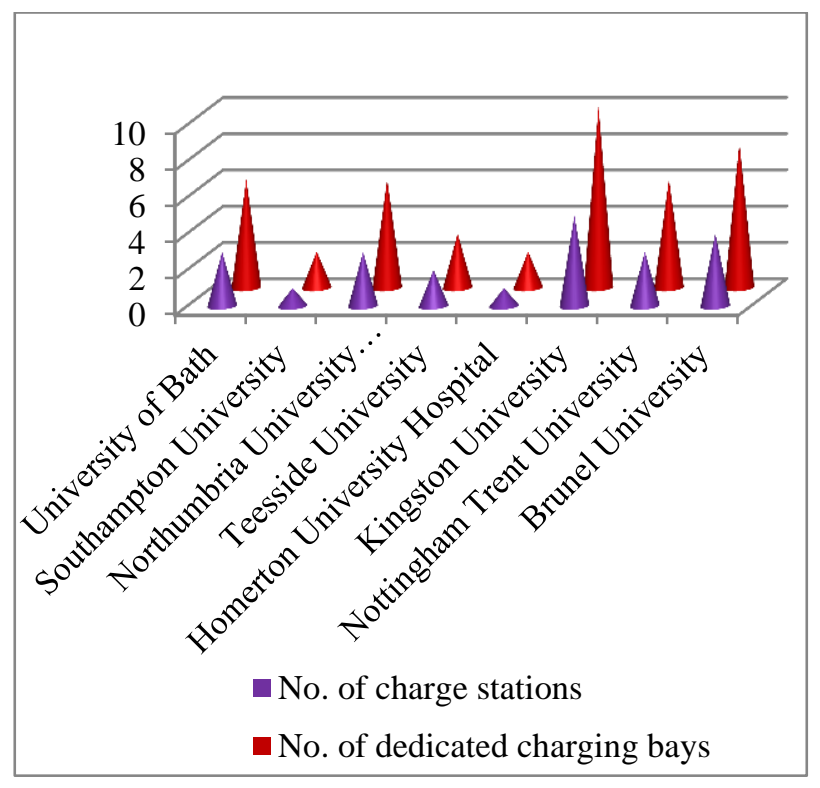

Fig.5. Number of charging stations and dedicated charging bays at HEI's

\section{RECOMMENDATIONS}

\section{A. Tariff and Hours of Operation}

To help Brunel students, staff and visitors continue to get the most from their electric vehicles -for less- a special tariff is introduced. With this special rate of $11.8 \mathrm{p} / \mathrm{kWh}$ an $\mathrm{EV}$ can be charged at a cheaper rate. This finalised tariff is what exactly the university pays to the electricity providers.

Example: Nissan Leaf has $24 \mathrm{kWh}$ battery which when connected to $32 \mathrm{~A}$ socket takes 4 hours to fully charge. For every 
1 hour, $6 \mathrm{kWh}$ is delivered and $6^{*} 0.118=£ 0.708$ is payable. Fully charging a Nissan Leaf costs $£ 2.832$ at $11.8 \mathrm{p} / \mathrm{kWh}$

This charging facility on campus can be made available 24/7. There is a customer support line for all EV drivers using these posts at all times and the user can call on 02072474114 if they have any charging problems.

\section{B. Effective operation of parking and identification of EV}

A specially designed sticker must be issued to the EV owners to be displayed along with the parking permit in the windscreen of the car or a parking permit with a colour different to that of existing permit colours which are used to differentiate students and staff. Following one of the above mentioned phenomena it will be easy to identify an EV and an effective operation of parking can take place.

\section{Incentive}

Brunel University is extremely proactive in encouraging the usage of Electric Vehicles. The strong indication of Brunel's commitment to zero carbon emission vehicles is the establishment of Pod Points. Brunel University also encourage the EV owners through incentives. The incentives recommended were as follows:

a. 50\% concession in the parking permit fee and provide few reserved parking spaces for Electric vehicles in addition to the dedicated charging bays. These reserved parking spaces must be made available only for EV's of Brunel students \& staff during work hours.

b. $50 \%$ concession in the parking permit fee and allow the EV to be parked in both standard white bays (allotted for students to park their cars) and the bays marked with a red dot (reserved for staff).

c. No concession in the parking permit fee. Allow the EV to be parked in both standard white bays and the bays marked with a red dot. All the EV owners can be invited for lunch and award them with a certificate of appreciation once annually.

In addition to the above, free loan of charging cable to the EV owners is suggested to be made available.

\section{Enforcement}

EV owners who use the parking while charging facility at the university must obey the terms mentioned below else penalty charge notice $(\mathrm{PCN})$ will be issued. a. For any non-electric vehicles parked within the designated bays for the purpose of charging an electric vehicle.

b. For the electric vehicles if they are not being charged when parked in the designated bays.

c. If every part of the vehicle is not within the charging bay.

d. For the non-compliance of existing Traffic, Parking and Permit regulations of the university.

\section{CONCLUSION}

Brunel is going to be the first flexible PAYG charging station provider. Brunel will set an example and can be taken as reference by other HEI's in smooth running of the facility at their premises once they start switching over to PAYG network. The consultation process with the present and prospective EV owners gave wide opportunity to discuss and debate various topics. Benchmarking helped to compare various parameters at several universities. Finding the parking space to park the car after charging and compatibility of the charging cable with charging stations are the most worried subjects. The entire concerns rose during the consultation process and the key findings from benchmarking were given serious consideration while framing the recommendations. This research is part of travel plan implementation promoting sustainable mode of transport to and from the university.

\section{REFERENCES}

[1] T. D. Sole and G. Bist, "Benchmarking in Technical Information," IEEE Transactions on Professional Communication, vol. 38, no. 2, pp. 77-82, 1995.

[2] P. Point, "User Guide:Pod Point twin charge,” December 2013. [Online]. Available: www.pod-point.com/wp-content/uploads/2011/08/POD-PointStreet-User-Guide-V9.pdf. [Accessed December 2013].

[3] P. Point, "Datasheet:Pod Point twin mennekes 32-32 PP 21511 PP," December 2013. [Online]. Available: http://www.pod-point.com/wpcontent/uploads/2011/08/PP-DATASHEET-twin-charge-32-32.pdf. [Accessed December 2013].

[4] P. Point, "POD Point Pay As You Go (PAYG) Network: Confidential," Pod Point Ltd, London, 2013.

[5] P. Point, "Using public charging networks," December 2013. [Online]. Available:http://www.pod-point.com/markets/ev-driver/using-publiccharge-networks/. [Accessed December 2013].

[6] P. Point, “The POD Point PAYG Network," December 2013. [Online]. Available:http://www.pod-point.com/markets/public/openchargenetwork/. [Accessed December 2013]. 